Interactive influence of experience, qualification, and gender on elementary school teachers' attitudes towards external supervision of instruction

Igwebuike, Thomas B.

College of Education, Warri, Nigeria (dadaigwebuike@yahoo.com)

Okandeji, Comfort O.

College of Education, Warri, Nigeria (cokandeji@yahoo.com)

Onwuegbu, O. C.

College of Education, Agbor, Nigeria (okeyonwuegbu@yahoo.com)

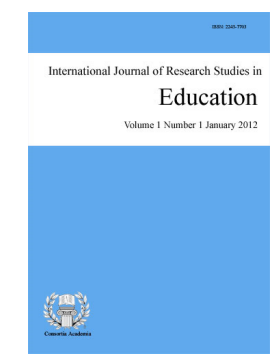

ISSN: 2243-7703 Online ISSN: 2243-7711

OPEN ACCESS

\title{
Abstract
}

Several studies have been conceptualized to determine the efficacy of supervision of schools in general, and instruction in particular, by external supervisors, and have produced strands of evidence which converge to conclude that the exercise has not been effectively carried out. It was speculated, in this study, that such laxity could influence teachers' attitudes towards external supervision of instruction and that the influence could depend on some teacher variables and their interactions. Using 300 subjects drawn from a pool of elementary school (grades 1-6) teachers in Warri municipality, Nigeria and an instrument designed and validated for this purpose, it was found that experience and qualification significantly influenced their attitudes while gender did not. It was also found that experience by qualification, and qualification by gender interactions were significant. Both ordinal and dis-ordinal interactions were observed when these interactions were plotted using the various group means. The implications of these results for supervision of instruction by external supervisors and for further research are addressed in this article.

Keywords: elementary school; supervision of instruction; teachers' attitudes 


\section{Interactive influence of experience, qualification, and gender on elementary school teachers' attitudes towards external supervision of instruction}

\section{Introduction}

National (Nigeria) Policy on Education (NPE) (Federal Republic of Nigeria, 2004) states that the success of any system of education is hinged on proper planning, efficient administration and adequate financing and that administration is a function of organization and structure, proprietorship and control, inspection and supervision. Issues have been taken, over the years, with the federal and state governments over the grossly inadequate funding of education in Nigeria. For instance the budgetary allocation to education by the various governments is not up to 10 percent. This is far below 26 percent recommended by UNESCO. This has been a recurring nightmare to educational administrators, teachers at all levels of education and parents and guardians. Academic Staff Union of Nigerian universities have also made it a recurring issue in her series of industrial dispute with the federal and state governments over the years.

Another factor that determines the success of any system of education is efficient administration, according to the policy. This document also states that the objectives of planning, administrative, inspectorate, supervisory services, among others, are to:

$>$ provide efficient administrative and management control for the maintenance and improvement of the system; and

$>\quad$ ensure quality control through regular and continuous supervision of instructional and other educational services.

If these objectives are adequately pursued, stakeholders in education should be getting the value from their investment which, according to Igwebuike (2008), is what the society whose members are being educated perceives as desirable and worthwhile. But proper administration and management of schools is attainable in part through continuous monitoring and supervision of the performance of the schools through regular inspection by external supervisors from the ministry of education to ensure the schools are following the laid down objectives of education in the National Policy on Education (Idama, 2010). This is because the major duty of external supervisors of education is stimulating growth and helping teachers to achieve excellence in teaching (Obanor, 2009).

It is therefore disheartening to note the observation by Ogunu (2001), Alade (2002), Okpetu and Yesufu (2003), Arubayi (2006), and Obanor (2009) that supervision or monitoring of schools has not been taken seriously and so has been called to question within and outside the profession. Alade (2002) identifies some of the reasons for this laxity as inappropriate staffing of the inspectorate department, inadequate funding of the inspectorate and inadequate number of supervisors. Inadequate staffing of the inspectorate, as a reason is endorsed by Ogunu (2001) who, in an empirical study, revealed that only 6 out of 15 inspectors had degrees in education. He also reported that only $88 \%$ of the 150 respondents indicated that inadequate number of inspectors was serious constraint to school inspection. Irregular visit was also reported by Arubayi (2006). It can be conjectured that these and other reasons may influence elementary and secondary school teachers' attitudes towards external supervision of instruction.

Obanor (2009) assessed the attitudes of secondary school teachers in Warri metropolis of Nigeria towards instructional supervision by external supervisors. He found that $57.5 \%$ of the teachers $(N=200)$ agreed that external supervisors lord it over teachers instead of sharing ideas on how to improve teaching though $58.5 \%$ indicated that they feel good each time external supervisors visit their classes. Up to $83.5 \%$ said that they feel bad each time they observe that some external supervisors are not professional teachers. Up to $63.5 \%$ of the 
Interactive influence of experience, qualification, and gender on teachers' attitudes towards external supervision teachers felt that the objectives of supervision will not be achieved because of the way supervisors do their work. Idama (2010) studied the same phenomenon among elementary school teachers and arrived at similar findings. Her findings further indicated that while there was no statistically significant difference in attitude towards external supervision of instruction between male and female elementary school teachers, significant differences in attitudes were found between experienced and in-experienced teachers, and qualified and non-qualified teachers in favor of experienced and non-qualified teachers. But Obanor (2009) working on the secondary school teachers, found that gender, experience and qualification did not significantly influence their attitudes towards external supervision of instruction. Okandeji (2011) provide findings which support these results' should be added.

A rekindle interest on the study of the influence of these variables on attitudes of teachers towards external supervision of instruction could lead to hunches on the interactive influences of these variables. It may be possible that there would be interaction of these factors or variables. The need to study the nature of these interactions may precipitate, to the intent of determining whether single statements can be made about the interactions of these variables or whether reference will be made to a level of each of the variables while exposing their influences. These aptly describe the objectives of this study. Consequently, the study will focus on the main effects of these variables and their interactions.

\subsection{Research questions}

Specifically, the following research questions were addressed in this study:

$>\quad$ Is there any significant difference in attitude towards external supervision of instruction between experienced and inexperienced elementary school teachers?

$>\quad$ Is there any significant difference in attitude towards external supervision of instruction between qualified and non-qualified elementary school teachers?

$>\quad$ Is there any significant difference in attitude towards external supervision of instruction between male and female elementary school teachers?

$>\quad$ Are there any significant interaction effects of experience by qualification, experience by gender, gender by qualification, and experience by qualification by gender?

\section{Method}

\subsection{Population and sample}

The population of this study consisted of elementary school teachers in Warri metropolis. Warri, with a population of about 150,000, is a city in the southwest of Nigeria in West Africa. It is located in Delta State and it is the most populous city in the State. It is one of the few coastal towns in Nigeria whose populations have increased tremendously because of global expansion in oil and gas exploration. The inhabitants are increasingly becoming aware of the need to prepare their children and wards for careers in the oil and gas industry. The demand for quality education at all levels is therefore very high. A sample of 300 elementary school teachers was selected using stratified random sampling technique from Warri metropolis. The strata used were experience, qualification and gender. An experienced teacher, in the context of this study is an elementary school teacher who has taught in the elementary school system for at least 10 years while a qualified teacher is an elementary school teacher who holds at least a bachelors' degree in education or Post Graduate Diploma in Education.

\subsection{Instrument}

An instrument, Teacher Attitude Towards Supervision of Instruction (TATOSI) was developed by Igwebuike 
Igwebuike, T. B., Okandeji, C. O., \& Onwuegbu, O. C.

(2009). The instrument has 6 scales with each scale having 5 items. The scales are; Conception of Supervision, Nature of Relationship Between Teachers and Supervisors, Qualification and Experience of Supervisor, Meeting the Objectives of Supervision, Mentoring and Quality Advice, and Supervision of Teaching. The responses to the items are structured using Likert response model of Strongly Agree (SA), Agree (A), Disagree (D), and Strongly Disagree (SD). The scoring was 4, 3, 2, 1 for SA, A, D, and SD respectively for positively stated items. The scoring was reversed for negatively stated items. A total score for each respondent was determined by adding all the points for the item. A sample of the items per scale is provided in Table 1.

\section{Table 1}

A sample of the items

\begin{tabular}{llll}
\hline \multicolumn{1}{c}{ Scale } & & \multicolumn{1}{c}{ Item } \\
\hline 1. & Conceptions of Supervision & (i) & $\begin{array}{l}\text { I feel happy with external supervisors } \\
\text { because they guide me to make my teaching } \\
\text { better } \\
\text { Supervisors make their work evaluative and I } \\
\text { like that }\end{array}$ \\
\hline 2. & Nature of Relationship & (ii) & (i) $\begin{array}{l}\text { I feel good each time a supervisor visits } \\
\text { (ii) }\end{array}$ \\
\hline 3. & Qualification and Experience of Supervisors & (i) $\begin{array}{l}\text { I feel any educated person can supervise } \\
\text { teaching }\end{array}$
\end{tabular}

(ii) Much to my disgust some of the supervisors do not have teaching qualifications.

4. Meeting the Objectives of Supervision

(i) I feel the objectives of supervision will not be met because of the way supervisors do their work

(ii) My quality of teaching improves each time my teaching is supervised.

5. Mentoring and Quality Advice

(i) Supervisors acknowledge any good work I do and this inspires me to teach well.

(ii) Supervisors give me quality advice on how to improve my teaching.

6. Supervision of Teaching Generally

(i) Supervision is embarrassing because, most times, the teacher's work is criticized in the presence of the pupils

(ii) I am not excited by supervision because it does not improve my teaching.

A pilot study was carried out by Igwebuike (2009) on the instrument using a sample different from the sample used in the present study. This was done to ascertain the instrument went through all the pretests necessary. The instrument was found to have desired level of face and content validity. Cronbach alpha procedure was used for determining the reliability coefficients of the scales. These were found to range between 0.78 and 0.86 . The intra-scale consistency for the 6 scales ranged from $0.75-0.85$. A composite reliability index of 0.79 was obtained using the same procedure. This value is considered relevant since the respondents' scores were compositely determined in the present study.

\subsection{Procedure for data collection}

The instrument was administered to each of the 300 elementary school teachers in the sample by the researchers. The teachers were promised that their responses would be treated confidentially. There was replacement of the questionnaires not retrieved from the initial administration according to the characteristics of the subjects.

\subsection{Method for data analysis}

A 2 × 2 × 2 non-orthogonal (non-proportional) ANOVA was carried out and was observed at the 0.05 level 
of significance to find if there were significant main effects and interactions. To probe the nature of significant interactions (ordinal or dis-ordinal) and to make some visual impacts of these interactions, graphs were plotted using the various group means of the levels of interacting variables. Ordinality and dis-ordinality, according to Glass and Stanley (1970) are properties of graphs. A choice exists between placing any of the interacting variables on the abscissa while graphing the interaction. The same cell means can give an ordinal interaction when one of the variables is placed on the abscissa and a dis-ordinal interaction when the other variable is placed on the abscissa. Consequently, two graphs were plotted for each pair of the interacting variables. The first placed one variable on the abscissa while the second placed the other variable on the abscissa.

\section{Table 2}

Means and SDs according to levels of variable

\begin{tabular}{|c|c|c|c|c|c|}
\hline & & & \multicolumn{2}{|c|}{ Experience } & \multirow[b]{2}{*}{ RT } \\
\hline & & & Experienced & In-experienced & \\
\hline \multirow{4}{*}{ 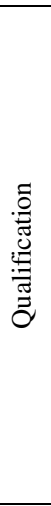 } & \multirow{2}{*}{ 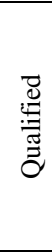 } & Male & $\begin{array}{l}\mathrm{n}=35 \\
\bar{x}=79.60 \\
\mathrm{SD}=7.62\end{array}$ & $\begin{array}{l}\mathrm{N}=34 \\
\bar{x}=81.11 \\
\mathrm{SD}=5.02\end{array}$ & $\begin{array}{l}\mathrm{n}=69 \\
\bar{x}=80.36 \\
\mathrm{SD}=6.32\end{array}$ \\
\hline & & Female & $\begin{array}{l}\mathrm{n}=39 \\
\bar{x}=80.11 \\
\mathrm{SD}=7.92\end{array}$ & $\begin{aligned} \mathrm{N} & =41 \\
\bar{x} & =80.36 \\
\mathrm{SD} & =4.21\end{aligned}$ & $\begin{array}{l}\mathrm{n}=80 \\
\bar{x}=80.24 \\
\mathrm{SD}=6.07\end{array}$ \\
\hline & \multirow{2}{*}{ 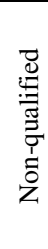 } & Male & $\begin{array}{l}\mathrm{n}=36 \\
\bar{x}=83.63 \\
\mathrm{SD}=7.88\end{array}$ & $\begin{array}{l}\mathrm{N}=35 \\
\bar{x}=78.50 \\
\mathrm{SD}=4.41\end{array}$ & $\begin{array}{l}\mathrm{n}=71 \\
\bar{x}=81.07 \\
\mathrm{SD}=6.15\end{array}$ \\
\hline & & Female & $\begin{aligned} \mathrm{n} & =37 \\
\bar{x} & =87.57 \\
\mathrm{SD} & =7.57\end{aligned}$ & $\begin{array}{l}\mathrm{N}=38 \\
\bar{x}=79.94 \\
\mathrm{SD}=4.88\end{array}$ & $\begin{array}{l}\mathrm{n}=75 \\
\bar{x}=83.76 \\
\mathrm{SD}=6.23\end{array}$ \\
\hline & & CT & $\begin{array}{l}\mathrm{n}=152 \\
\bar{x}=82.88 \\
\mathrm{SD}=7.75\end{array}$ & $\begin{array}{l}\mathrm{N}=148 \\
\bar{x}=79.99 \\
\mathrm{SD}=4.63\end{array}$ & \\
\hline
\end{tabular}

\section{Results}

Table 3 indicates that experience and qualification had significant main influences on the elementary school teachers' attitudes towards external supervision of instruction $\left[\mathrm{F}_{(1,292)}=15.68, p<0.05\right]$ and $\left[\mathrm{F}_{(1,292)}=9.30, p<0.05\right]$ respectively, while gender did not have significant main influence $\left[\mathrm{F}_{(1,292)}=3.44, p>0.05\right]$. This means that the experienced elementary school teachers with higher group mean score had more positive attitude towards external supervision of instruction than their counterparts who are inexperienced. Non-qualified elementary school teachers had more positive attitude towards external supervision of instruction than their counterparts who are qualified. Table 3 indicates that there was no significant difference in attitude towards external supervision of instruction between the male and female elementary school teachers. Table 3 also indicates that there were significant interaction effects of experience by qualification, and qualification by gender while there were no interaction effects of experience by gender and experience by qualification by gender. Graphs were plotted to create some visual impacts, and as mentioned under 'methods for Data Analysis' to determine the nature of interaction.

Figure 1 in which experience is placed on the abscissa indicates that the line segments connecting the group means cross. This means that the interaction is dis-ordinal and by implication, non-qualified experienced elementary school teachers had more positive attitude towards external supervision of instruction than qualified experienced teachers. The same Figure 1 indicates that qualified inexperienced elementary school teachers had better attitude towards external supervision of instruction than their non-qualified inexperienced counterparts. Figure 2 in which qualification was placed at the abscissa, indicates that inexperienced qualified elementary school teachers had superior attitude towards external supervision of instruction than experienced qualified elementary school teachers. It also shows that experienced non-qualified teachers had superior attitude towards external supervision of instruction than inexperienced non-qualified teachers. The implication of the graphs in 
Igwebuike, T. B., Okandeji, C. O., \& Onwuegbu, O. C.

Figures 1 and 2 is that irrespective of the variable (experience and qualification) placed on the abscissa we cannot make a single statement about the superiority of two levels of each of the variables.

\section{Table 3}

ANOVA summary

\begin{tabular}{|c|c|c|c|c|}
\hline Source & $S S$ & $d f$ & MS & $F$ \\
\hline \multicolumn{5}{|l|}{ Main Effect } \\
\hline Experience & 565.539 & 1 & 565.539 & $15.682 *$ \\
\hline Qualification & 335.458 & 1 & 335.458 & $9.302 *$ \\
\hline Sex & 124.205 & 1 & 124.205 & $3.444 * *$ \\
\hline \multicolumn{5}{|l|}{ 2-way interaction } \\
\hline Experience $\mathrm{x}$ qualification & 985.266 & 1 & 985.266 & $27.320 *$ \\
\hline Experience $\mathrm{x}$ sex & 66.217 & 1 & 66.217 & $1.836 * *$ \\
\hline Qualification $\mathrm{x}$ sex & 148.528 & 1 & 148.528 & $4.119 *$ \\
\hline \multicolumn{5}{|l|}{ 3-way interaction } \\
\hline $\begin{array}{l}\text { Experience } \mathrm{x} \text { qualification } \mathrm{x} \\
\text { sex }\end{array}$ & 7.288 & 1 & 7.288 & $.202 * *$ \\
\hline Error & 10530.548 & 292 & 36.064 & \\
\hline Total & 2003409.000 & 300 & & \\
\hline Corrected Total & 12852.437 & & & \\
\hline
\end{tabular}

Table 4

Group means of experience and qualification used for plotting graphs

\begin{tabular}{lcc}
\hline & \multicolumn{2}{c}{ Experience } \\
& Experienced & In-experienced \\
\hline Qualified & 80.36 & 80.73 \\
Non-qualified & 85.65 & 79.22 \\
\hline
\end{tabular}

\section{Table 5}

Group means of qualification and gender for plotting graphs

\begin{tabular}{lcc}
\hline & \multicolumn{2}{c}{ Qualification } \\
& Qualified & Non-qualified \\
\hline Male & 80.35 & 81.55 \\
Female & 80.24 & 83.76 \\
\hline
\end{tabular}

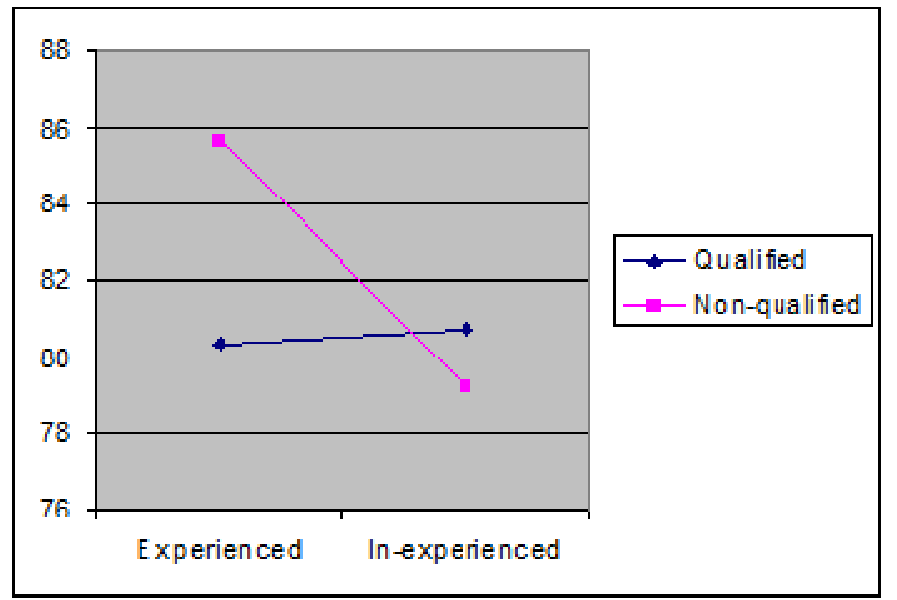

Figure 1. Graph of group means with experience on the abscissa 


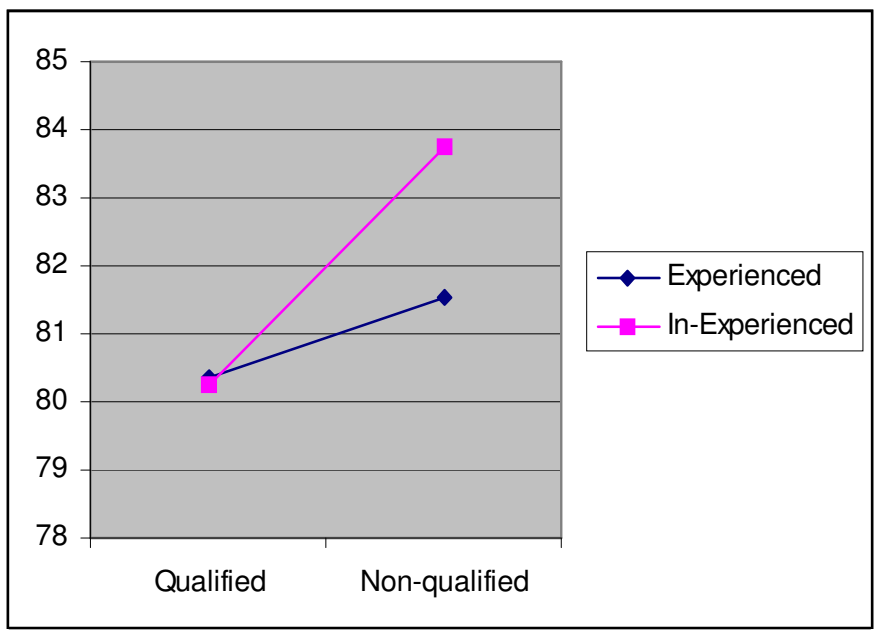

Figure 2. Graph of group means with qualification on the abscissa

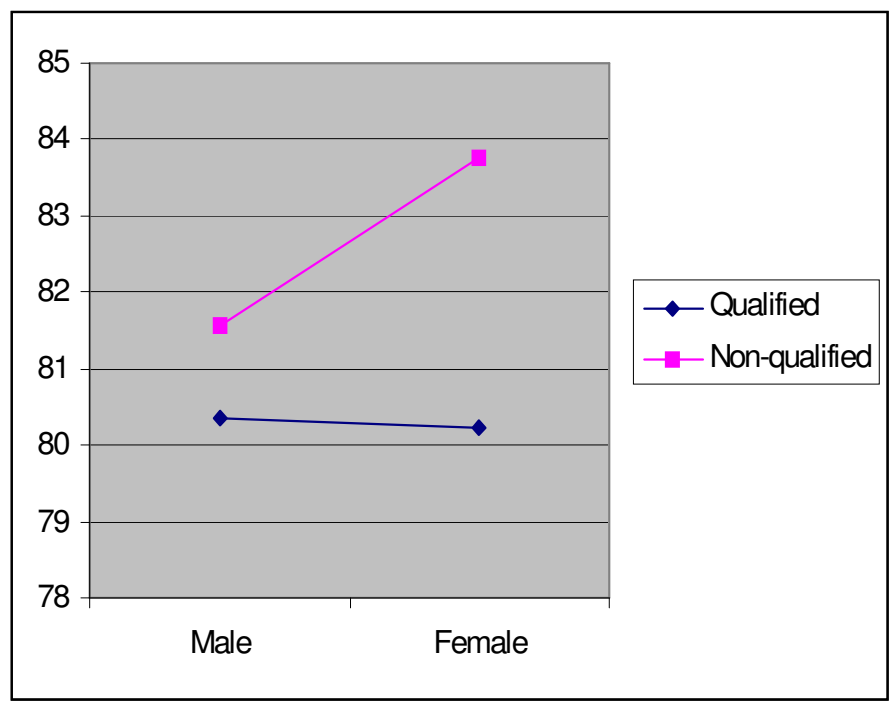

Figure 3. Graph of groups means with gender on the abscissa

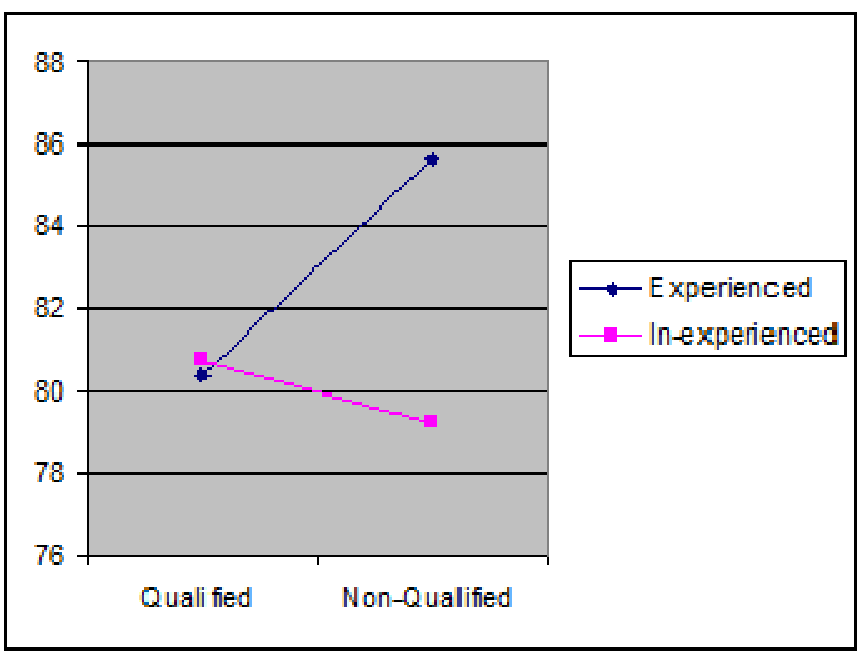

Figure 4. Graph of group means with qualification on the abscissa 
Igwebuike, T. B., Okandeji, C. O., \& Onwuegbu, O. C.

Figure 3 shows that the line segments do not cross. The interaction is therefore ordinal. It should be noted that gender is placed on the abscissa. The implication of the ordinality observed here is that non-qualified male elementary school teachers had more superior attitude towards external supervision of instruction than qualified male teachers, and non-qualified female teachers had superior attitude than qualified female elementary school teachers. In other words, irrespective of gender non-qualified elementary school teachers had better attitude towards external supervision of instruction than their qualified counterparts. Figure 4, in which qualification is placed on abscissa, indicates that the interaction is dis-ordinal. Male qualified elementary school teachers had more positive attitude towards external supervision of instruction than their female qualified counterparts. But female non-qualified elementary school teachers had more positive attitude towards external supervision of instruction than their male non-qualified counterparts.

\section{Discussion and implications}

The purpose of this study was to determine whether experience, qualification and gender would have any significant influence on the elementary school teachers' attitudes towards external supervision of instruction. It also aimed at finding out if there would be significant interaction effects of these variables on such attitudes and the nature of interactions. Data obtained indicate that there is a significant difference in attitude towards external supervision of instruction between experienced and in-experienced elementary school teachers $\left[\mathrm{F}_{(1,292)}=15.68\right.$, $p<0.05]$ in favor of experienced teachers. This agrees with the findings of a study carried out by Idama (2010) which indicated that experienced teachers had more positive attitude towards external supervision of instruction. But Obanor's (2009) study which indicated that there was no significant difference between experienced and in-experienced secondary school teachers in their attitudes towards external supervision of their teaching provides a stark contrast. The result was expected from the present study and can be explained speculatively by the fact that long years of teaching experience may have induced some stabilization by the teachers about external supervision of instruction. It is likely too that the external supervisors have more cordial relationship with the experienced teachers some of whom may have been their contemporaries in the teaching field before they got deployed to the inspectorate division of the ministry of education.

Data obtained also indicate that elementary school teachers' qualification significantly influenced their attitude towards external supervision of their teaching $\left[\mathrm{F}_{(1,292)}=9.30, p<0.05\right]$ in favour of non-qualified elementary school teachers. This result is in accord with that established by Idama (2010). She found that non-qualified teachers had more positive attitude towards external supervision of instruction than their qualified counterparts. Obanor's (2009) study indicated that there was no significant difference in attitudes towards external supervision of instruction between qualified and non-qualified secondary school teachers. This result contradicts Peretomode's (1998) assumption that a professionally qualified teacher is more likely to understand the role of supervision and its impact on educational activities of the school. The result was not expected but can be explained by the fact that non-qualified teachers can more easily appreciate the importance of interaction with external supervisors towards improving their teaching performance since they did not have pre-service professional development. Pre-service professional development was expected to make some significant impact on their attitude towards supervision of instruction whether externally or internally. It is heart-warming to observe that they had more positive attitude towards external supervision of instruction than their qualified counterparts. This result confirms some recent criticisms of teacher education programs in the country (Igwebuike, 2009; Igwebuike \& Okandeji, 2009; Igwebuike, Okandeji, \& Ekwevugbe, 2011).

With respect to the influence of gender, it was found that there was no significant difference in attitudes towards external supervision of instruction between male and female elementary school teachers $\left[\mathrm{F}_{(1,292)}=3.44\right.$, $p>0.05]$. This is in accord with findings by Obanor (2009) and Idama (2010) which indicated that male and female secondary and elementary school teachers respectively do not differ in their attitudes towards external supervision of instruction. It was expected that female elementary school teachers would have more positive attitude towards external supervision of instruction because females have, generally, more positive attitude towards teaching than males (Ovwighose, 2010). The result can be explained in part, by the fact that there is a 
widespread apathy among elementary school teachers in Nigeria to their teaching job because state and local governments do not promptly and adequately take care of their welfare.

Probe of nature of interactions indicated that non-qualified experienced elementary school teachers had better attitudes to external supervision of instruction than qualified and experienced elementary school teachers (See Figure 1). The figure also indicates that qualified inexperienced elementary school teachers have more positive attitude towards external supervision of instruction than non-qualified inexperienced elementary school teachers. While the first revelation from the figure is an aberration, the second conforms to expectation. Qualification, as used in this context, presumes that a qualified teacher has undergone a professional preparation not below first degree in education. In this case, the recipient has developed knowledge of educational administration and teaching skills that should improve his attitude towards interacting with others to further improve his teaching skills and competences. It is not heart-warning therefore, to observe that non-qualified experienced elementary school teachers had better attitudes than their qualified experienced counterparts. This calls to question the efficacy of teacher education programs, as pointed out by Igwebuike (2009) and Igwebuike and Okandeji (2009). It can be explained speculatively; by the fact that many of the external supervisors are not qualified for the job they are doing (Ogunu, 2001). The qualified and experienced elementary school teachers may see the external supervision of instruction as an exercise in which the blind is leading a one-eyed person.

Figure 2 shows that experienced non-qualified elementary school teachers had more positive attitude towards external supervision of instruction than their inexperienced non-qualified counterparts. This result was expected because experience has been shown to improve attitudes towards external supervision of instruction (Idama, 2010) though Obanor's (2009) study does not support this. But the result contradicts the second observation that inexperienced qualified teachers had better attitude than experienced qualified teachers. It can be explained by a speculation that inexperienced qualified teachers generally have more zeal to learn on the job by interacting with external supervisors, among others.

It can be observed from Figure 3 that irrespective of gender, non-qualified elementary school teachers had better attitude towards external supervision of instruction than their qualified counterparts. This conforms to part of the observation in Figure 1 in which non-qualified experienced elementary school teachers had better attitude than their qualified counterparts. The same speculation given as explanation to the observation on that aspect of Figure 1 holds here. Figure 4 indicates that qualified male elementary school teachers had more positive attitude towards external supervision of instruction than qualified female elementary school teachers. This is contrary to the finding by Ovwighose (2010) that female teachers have more positive attitude to teaching. The result can be explained, perhaps, by a speculation that male elementary school teachers may have developed a better way of managing the stress concomitant upon external supervision of instruction. This is supported by the finding by Obanor (2009) and Idama (2010) that majority of the secondary and elementary school teachers, respectively, agreed that external supervisors lord it over the teachers instead of sharing ideas on how to improve teaching.

Figure 4 indicates that female non-qualified elementary school teachers had better attitudes towards external supervision of instruction than their male counterparts. This finding is supported by Ovwighose (2010) study in which she found that female teachers have more positive attitude to teaching. An implication of the results of this study is that there is the need to organize fora like seminars, conferences, workshops and symposia for elementary school teachers irrespective of their qualification, experience and gender to interact with supervisors from the State Inspectorate Department and teacher educators. Such fora should have environments that will allow the teachers to interact freely without anxiety and stress that have characterized such interactions in the past.

Clearly noteworthy is the result that non-qualified elementary school teacher had better attitude towards external supervision of instruction than their qualified counterparts. In this direction too, it should be noted that in the interaction analysis, non-qualified experienced elementary school teachers had better attitude towards external supervision of instruction than their counterparts that are qualified. Similarly, non-qualified male 
Igwebuike, T. B., Okandeji, C. O., \& Onwuegbu, O. C.

teachers and non-qualified female teachers have more positive attitude towards external supervision of instruction than qualified male teachers and qualified female teachers respectively. This means that elementary school teachers' qualification is further implicated. By implication, attention should be paid to qualified teachers in any attempt to improve attitudes of elementary school teachers towards external supervision of instruction.

One of the objectives of planning, administrative, inspectorate, supervisory services, is to ensure quality control through regular and continuous supervision of instructional and other educational services (Federal Republic of Nigeria, 2004). This objective cannot be attained if elementary school teachers, irrespective of their characteristics, do not have positive attitude towards external supervision of instruction. This study has suggested a direction to follow in attempts to potentiate elementary school teachers' attitudes towards external supervision of instruction.

\section{Conclusion}

The study provides evidence in support of the conclusion that experienced elementary school teachers have more positive attitude towards external supervision of instruction than their counterparts who are inexperienced. It also supports the conclusion that non-qualified elementary school teachers have more positive attitude than their qualified counterparts. Gender did not polarize the teachers' attitudes towards external supervision of instruction. The fragmentary data that have been presented in this paper are suggestive rather than conclusive. On a cautionary note, generalization of the present results cannot be made beyond the population of the study. Other studies, which will increase the sample size and scope, are needed to further pursue this line of inquiry to validate the findings of this study. Confirmatory studies should be carried out on the instrument used in this study to determine the factorial purity or mutual exclusivity of the items in the various scales. Nevertheless, our findings suggest the usefulness of the general direction of enquiry attempted in this study.

\section{References:}

Alade, O. M. (2002). An evaluation of the Inspectorate Department of the Lagos State (Nigeria) Ministry of Education. Unpublished Doctoral dissertation, University of Ibadan, Nigeria.

Arubayi, E. A. (2006). Regularity visits of education inspectors to elementary and secondary schools in Delta and Edo States (Nigeria). DELSU Journal of Educational Research and Development, 5(1), 29-36.

Federal Republic of Nigeria (2004). National policy on education (4th ed.). Lagos: Nigeria Educational Research and Development Council.

Glass, G. V., \& Stanley, J. C. (1970). Statistical methods in education and psychology. Englewood Cliffs, NJ: Prentice-Hall Inc.

Idama, A. (2010). Elementary school teachers' attitudes towards supervision of instruction by external supervisors. Unpublished Bachelor in Education Degree Project, Delta State University Abraka, Delta State- Nigeria.

Igwebuike, T. B., \& Okandeji, C. O. (2009). Traditional and contemporary conceptions of teaching: Implications for revamping teacher education programs in Nigeria for Vision 20-2020. Paper presented at the 2009 Annual National Conference of the School of Education, College of Education, Warri, Nigeria.

Igwebuike, T. B. (2008). Curriculum planning and development: Principles and practice (2nd ed.). Ughelli, Nigeria: Eregha Publishers.

Igwebuike, T. B. (2009). Development of an instrument for measuring teachers' attitudes towards supervision of teaching by external supervisors. A research paper, College of Education, Warri, Nigeria.

Igwebuike, T. B., Okandeji, C. O., \& Ekwevugbe, O. C. (2011). Teacher educators' conceptions of teaching and learning in teacher education institutions. A research paper, College of Education, Warri, Nigeria.

Obanor, E. R. (2009). Attitudes of secondary school teachers towards external supervision of instruction. A PGDE Project University of Port Harcourt, Nigeria.

Ogunu, M. A. (2001). Problems of school inspection in Nigeria. In current issues in educational management in Nigeria. National Association of Educational Administration and Planning (NAEAP), 270-281. 
Interactive influence of experience, qualification, and gender on teachers' attitudes towards external supervision

Okandeji, C. O. (2011). Attitudes of secondary school teachers towards external supervision of instruction. A seminar paper, Delta State University, Abraka, Nigeria.

Okpetu, S. A., \& Yesufu, J. T. (2003). Introduction to educational management and administration. Warri, Nigeria: COEWA Publishers.

Ovwighose, A. (2010). Attitudes of senior secondary school students towards teaching as a profession. Unpublished Masteral thesis, University of Port-Harcourt, Nigeria.

Peretomode, V. F. (1998). Introduction to educational planning and supervision. Lagos, Nigeria: Joja Educational Research and Publishers Ltd. 
Igwebuike, T. B., Okandeji, C. O., \& Onwuegbu, O. C. 